Given the lack of research on the role of geography in mental health care, this symposium presentation discusses whether racial/ethnic differences in mental health care vary across geographic regions among racially/ethnically diverse older adults in the U.S. Results from three studies using secondary datasets are presented. Study 1 discusses findings on significant geographic variation of Black-White disparities in mental health service use. Study 2 discusses findings on significant geographic variation of racial/ethnic differences in satisfaction with and perceived benefits from mental health services. Study 3 discusses findings on methodologies of identifying hot spots for disparities in mental health services, as well as hot spot areas for mental health services by race/ethnicity. The findings from the three studies suggest that to reduce racial/ethnic disparities at the national level, improving the access to mental health care in certain areas may be essential.

\section{INTEGRATION OF PEER PHILOSOPHY INTO A STANDARDIZED SELF-MANAGEMENT MOBILE HEALTH INTERVENTION}

K. Fortuna, Geisel School of Medicine at Dartmouth, Lebanon, New Hampshire, United States

Objective: Description of older certified peer specialists (aged 50+) integration of peer philosophy into the delivery of a integrated medical and psychiatric self-management intervention enhanced with mobile health for older adults with serious mental illness. Methods: Qualitative examination of peer case notes that were routinely entered on a peer care management electronic dashboard. This study included consumers with serious mental illness $(\mathrm{N}=8)$ with a mean age of 68.8 years $(\mathrm{SD}=4.9)$. Certified peer specialists $(\mathrm{N}=3)$ were all female and aged 55 years or older. Results: Peers entered 146 case notes on the peer care management notes dashboard. Five themes emerged including encouragement of self-determination, bio-psychosocial-spiritual framework guides practice, sharing lived experience to teach self-management skills, personalized text messages to reinforce self-management skill development, and identifying unmet needs and advocating for human rights. Conclusions: Peers unique perspectives and expertise was complemented with the standardized delivery of evidence-based intervention enhanced with mobile health.

\section{SESSION 2790 (SYMPOSIUM)}

\section{WORK AND RETIREMENT IN OLD AGE: NORMATIVE PATHS AND INDIVIDUAL AGENCY}

Chair: J. Heckhausen, University of California-Irvine, Irvine, California

Co-Chair: J. Hamm, University of California, Irvine, Irvine, California

The globalized and increasingly volatile world economy has destabilized normative career paths spanning adulthood and early old age. To be successful, individuals need to take more initiative in shaping their own careers and to respond to challenges associated with aging-related constraints in work demands and job conditions. Research presented in this symposium addresses the regulatory strategies used by middleaged and older adults to optimize or retire from their work life, and what the developmental outcomes of these strategies are. Fasbender, Wang, Wöhrmann, and Klehe studied older workers' career adaptability and personal growth as a function of occupational future time perspective and aging experience. Thrasher, Rudolph, Baltes, and Demsky investigated individual profiles of selection, optimization, and compensation in older workers. Hamm, Heckhausen, Shane, and Lachman examine whether continued employment versus retirement protects against cognitive declines in middle-aged and older adults, depending on goal disengagement and sex. Finally, Shane, Hamm, and Heckhausen address engagement in the work domain as it relates to chronological and subjective age, and both past developments and future expectations about one's work. After attending this session, participants will be able to define concepts associated with agency and control in work and retirement contexts. Participants will also learn about the implications of agency and control for adaptation and well-being in older adulthood.

\section{DOES REMAINING EMPLOYED IN MIDLIFE AND OLD AGE PROTECT AGAINST LOSSES IN COGNITIVE FUNCTIONING? A COMPARISON OF MATCHED SAMPLES}

J. Hamm ${ }^{1}$, J. Heckhausen, $\mathrm{PhD}^{2}$, J. Shane, $\mathrm{PhD}^{3}$, M.E. Lachman, $\mathrm{PhD}^{4}, 1$. University of California, Irvine, Irvine, California, United States, 2. University of California, Irvine, Irvine, CA, USA, 3. Brooklyn College, The City University of New York, New York, NY, USA, 4. Brandeis University, Boston, MA, USA

The present research examined whether remaining employed protected against nine-year declines in cognitive functioning (episodic memory). We used the national Midlife in the United States Study to (a) propensity score match middle-aged and older adults who remained employed with those who retired, (b) test whether the matched samples differed on longitudinal cognitive functioning, and (c) examine whether effects of work status were moderated by goal disengagement and sex. Comparisons of the matched samples indicated workers had slightly less decline in cognitive functioning than retirees, but this difference was not significant. Tests of moderation showed those who remained employed (vs. retired) exhibited more adaptive changes in cognitive functioning only if they were high in goal disengagement $(b=.26, p=.019)$ or if they were female $(b=.24$, $\mathrm{p}=.022$ ). Findings suggest that continued employment may protect against cognitive declines for women and those who are prone to goal disengagement after retirement.

\section{LATE CAREER PLANNING: CAREER ADAPTABILITY, AGING EXPERIENCE, AND OCCUPATIONAL FUTURE TIME PERSPECTIVE}

U. Fasbender ${ }^{1}$, M. Wang, $\mathrm{PhD}^{2}$, A.M. Wöhrmann, $\mathrm{PhD}^{3}$, $\mathrm{U}$. Klehe, $\mathrm{PhD}^{4}$, 1. Justus-Liebig-University Giessen, Gießen, Hessen, Germany, 2. University of Florida, Gainesville, FL, USA, 3. Federal Institute for Occupational Safety and Health (BAuA), Dortmund, Germany, 4. Justus-Liebig-

\section{University Giessen, Giessen, Germany}

We propose and test a model on older workers' career adaptability and aging experience (i.e., physical loss, social loss, personal growth, and gaining self-knowledge) as relevant factors shaping their late career planning. Moreover, we explore whether these relationships will be mediated 